\title{
OS IMPACTOS AMBIENTAIS E AS MELHORIAS OCORRIDAS APÓS O ACIDENTE DA PLATAFORMA P-36
}

\author{
L. S. MEIRA ${ }^{1}$, S. S. S. ANDRADE ${ }^{1}$ e L. D. SILVA $^{2}$ \\ ${ }^{1}$ Centro Universitário Jorge Amado, Departamento de Engenharia de Petróleo e Gás \\ ${ }^{2}$ Centro Universitário Jorge Amado, Departamento de Engenharia de Petróleo e Gás \\ E-mail para contato: losmeira@hotmail.com; suedsoraia@ hotmail.com.
}

\begin{abstract}
RESUMO - Nas plataformas de petróleo, as condições de trabalho são perigosas, resultando em acidentes de trabalho e, por vezes, em verdadeiras catástrofes. $\mathrm{O}$ presente artigo analisa $\mathrm{o}$ acidente na plataforma P-36 através do relatório emitido pela Agência Nacional do Petróleo em conjunto com a Marinha do Brasil. Este acidente foi um marco na história do Brasil, ocorreu no campo de Roncador, na Bacia de Campos, após a operação de esgotamento de água do tanque de drenagem de emergência da coluna de popa bombordo, ocorrendo duas explosões, resultando na morte de alguns funcionários da Petrobrás e afundamento completo da plataforma. Sendo assim, realizou-se um estudo sobre o relatório, onde inicialmente foram analisadas as possíveis causas do acidente e dessa forma foi possível adquirir subsídios para apresentar os impactos ambientais e as oportunidades de melhorias.
\end{abstract}

Palavras-chave: Plataforma P-36; Acidente; Causas; Melhorias.

\section{INTRODUÇÃO}

Plataformas de petróleo são instalações bastante complexas e algumas, principalmente as grandes plataformas, podem incluir a produção e armazenagem de óleo e gás à alta pressão, a perfuração de poços e obras de construção e manutenção (BOOTH e BUTLER, 1992).

A plataforma P-36, encontrava-se instalada no Campo de Roncador, descoberto em 1996 na Bacia de Campos, que estava sendo desenvolvido em três módulos, sendo que o primeiro módulo foi projetado para ter 28 poços interligados individualmente. Segundo ANP/DPC (2001) a plataforma estava ir ${ }^{\text {``}}$ lada em 
lâmina d'água de 1.360 metros, entrou em produção em maio de 2000 e tinha capacidade de processar 180.000 barris/dia de petróleo e comprimir 7,2 milhões de metros cúbicos/dia de gás natural.

Segundo o estudo feito por Souza (2006) a referida plataforma sofreu uma série de adaptações, para extrair petróleo a uma profundidade superior a inicial. Pelo projeto original, a plataforma iria operar numa lâmina d'água de até 500 metros. Com a modificação, tornou-se capaz de retirar petróleo a uma profundidade de 1.360 metros.

Durante a drenagem do tanque de emergência de bombordo, uma válvula que estava entreaberta ou danificada, deixou vazar óleo, água e gás para o segundo tanque, provocando a primeira explosão na coluna de popa boreste da plataforma P-36. Os fluidos do tanque rompido e demais equipamentos também danificados passaram a ocupar o compartimento do quarto nível da coluna. Devido à falha no sistema de ventilação e aberturas nesse compartimento ocorreu escapamento de gás para os níveis superiores da coluna ocasionando a segunda explosão no Top Tank e em áreas próximas, resultando na morte de alguns funcionários da brigada de incêndio da plataforma.

Dessa forma, o objetivo desse artigo é realizar uma análise do relatório emitido pela Agência Nacional do Petróleo em conjunto com a Marinha do Brasil visando apresentar os impactos ambientais e as melhorias ocorridas após o acidente da plataforma P-36.

Inicialmente serão discutidas as possíveis causas do acidente da plataforma P-36 que é o objeto de estudo desse artigo. Posteriormente, os impactos ambientais e as oportunidades de melhorias após o incidente serão apresentadas.

\section{CAUSAS DO ACIDENTE NA PLATAFORMA P-36}

Segundo estudo realizado pela ANP/DPC (2001), a análise das causas mais prováveis do acidente permitiu identificar o evento crítico como sendo a operação de esgotamento de água do tanque de drenagem de emergência da coluna de popa bombordo, iniciada na noite do dia 14 de março de 2001.

Observa-se que inicialmente ambos os tanques de drenagem de emergência de bombordo e boreste estão com cerca de metade da sua capacidade preenchida com água. No dia 14 de março é iniciado o procedimento para o esvaziamento do tanque de drenagem de emergência de bombordo, onde a água contaminada com resíduos oleosos presentes no tanque seria bombeada para o manifolde (header) de produção da plataforma e juntamente com os hidrocarbonetos, a água escoaria para a planta de processo. O 
operador tenta a partir da sala de controle central da plataforma partir a bomba de recalque, não tendo êxito na operação, pois a bomba só pode ser ligada através do comando local situado próximo a bomba, por medida de segurança.

Durante $50 \mathrm{~min}$ os tanques permanecem alinhados com a planta de processo sem a bomba de recalque do tanque de bombordo estar funcionando, por causa desse problema, ocorre fluxo reverso de hidrocarbonetos pelas linhas de escoamento dos tanques e sua entrada no tanque de boreste através de válvula presumivelmente danificada ou parcialmente aberta. O petróleo no momento que começa a entrar no tanque libera o gás dissolvido, aumentando sua pressão interna, pois o suspiro do tanque se encontrava bloqueado. Quando finalmente o operador consegue dar partida da bomba, diminui o fluxo reverso de hidrocarbonetos e a água bombeada passa a entrar no tanque de popa boreste.

Dessa forma, a pressurização contínua do tanque de boreste levou a seu rompimento mecânico ocorrendo assim à primeira explosão. Com a ruptura da parede interna, rompe-se também a tubulação de captação de água do mar, que fica ao lado do tanque, dessa forma começa a entrar no quarto nível da coluna água do mar, a água que estava no tanque e posteriormente o hidrocarboneto que estava armazenado no tanque de drenagem de emergência, o qual libera gás.

O nível da água com hidrocarboneto na superfície começa a subir rapidamente atingindo os ramais de ventilação, esses ramais levam através do tubo principal de ventilação o fluido para a sala de bombas existente no submarino. A porta estanque de acesso à coluna de popa boreste é aberta pela brigada de incêndio, sendo logo em seguida percebida uma névoa, a abertura da mesma facilita a migração do gás para os pisos superiores.

Em seguida são disparados os alarmes de alagamento da sala de bombas e sala de propulsores. O Top Tank também foi contaminado pelo gás liberado no quarto piso. Após a contaminação, ocorre a segunda explosão no Top Tank, causada pela combustão do gás seguida de incêndio. A explosão atinge a brigada de incêndio e destrói equipamentos, instrumentos localizados tanto na coluna como no Top Tank e no Second Deck. A seguir, a Tabela 1 lista as principais causas que marcaram essa tragédia com a plataforma p-36.

Tabela 1- Causas da catástrofe da plataforma P-36 


\begin{tabular}{|c|c|}
\hline Causa & Descrição \\
\hline $\begin{array}{l}\text { Problema na partida da bomba de recalque do } \\
\text { tanque de emergência de bombordo }\end{array}$ & $\begin{array}{l}\text { O operador tenta a partir da sala de controle central da } \\
\text { plataforma partir a bomba de recalque, não tendo } \\
\text { êxito na operação, pois a bomba só pode ser ligada } \\
\text { através do comando local. Dessa forma permitiu que } \\
\text { houvesse fluxo reverso do fluido pelas linhas de } \\
\text { escoamento dos tanques e sua entrada no tanque de } \\
\text { boreste. }\end{array}$ \\
\hline $\begin{array}{l}\text { Problema com a válvula de entrada do tanque de } \\
\text { emergência de boreste }\end{array}$ & $\begin{array}{l}\text { A válvula de entrada do tanque de boreste permitiu a } \\
\text { passagem de fluidos (hidrocarbonetos e água } \\
\text { contaminada) para seu interior, presumivelmente por } \\
\text { estar parcialmente aberta ou ter sido danificada. }\end{array}$ \\
\hline Falha no Sistema de Ventilação & $\begin{array}{l}\text { A migração de água para a parte inferior da coluna se } \\
\text { deu quando a água no compartimento do quarto nivel } \\
\text { atingiu os dampers do sistema de ventilação que } \\
\text { deveriam fechar automaticamente; porem, devido à } \\
\text { falha no funcionamento de seus atuadores, permitiram } \\
\text { a passagem de fluidos onde acabou ocasionando a } \\
\text { segunda explosão e morte da brigada de incêndio. }\end{array}$ \\
\hline $\begin{array}{l}\text { Localização do tanque drenagem de emergência em } \\
\text { uma das colunas da Plataforma }\end{array}$ & $\begin{array}{l}\text { O rompimento de tubulações, causado pela explosão } \\
\text { do tanque de drenagem de emergência de boreste } \\
\text { (primeira explosão), fez com que houvesse um grande } \\
\text { vazamento de água, óleo e gás que escoou para } \\
\text { compartimentos inferiores da plataforma, } \\
\text { posteriormente houve a segunda explosão na coluna } \\
\text { de boreste. }\end{array}$ \\
\hline $\begin{array}{l}\text { Rompimento dos tubos que transportavam água do } \\
\text { mar }\end{array}$ & $\begin{array}{l}\text { Após a primeira explosão, houve o rompimento dos } \\
\text { tubos que transportavam água do mar, por dentro da } \\
\text { coluna, para o sistema de combate a incêndio. Este } \\
\text { rompimento fez com que a coluna começasse a ser } \\
\text { inundada e não permitiu o funcionamento do sistema } \\
\text { de combate a incêndio. }\end{array}$ \\
\hline
\end{tabular}

A análise dos acontecimentos descrita na Tabela 1 acerca do acidente da plataforma conduziu à identificação de erros quanto a procedimentos regulamentares de operação, manutenção e projeto. Ainda foi possível observar outra falha quanto à manutenção, pois o sistema de ventilação deveria se fechar automaticamente e erro no projeto, pois a localização do tanque estava inadequada.

Sendo assim, a próxima seção deste artigo é destinada a apresentar os impactos ambientais causados pelo acidente, quanto de fluido foi derramado no oceano e o que foi feito para combater o derramamento.

\section{IMPACTOS AMBIENTAIS}

Quando ocorreu o acidente na plataforma P-36 tinha estocado a bordo e em suas linhas e vasos de produção uma grande quantidade de óleo diesel e petróleo bruto. Com o afundamento da mesma, os fluidos começaram a vazar para o oceano, a uma distância aproximada de $150 \mathrm{~km}$ da costa, tendo cerca de $350 \mathrm{~m}^{3}$ 
de óleo nas primeiras 24 h após o afundamento, segundo "Comunicação de Derramamento de Substância Poluente", de 21 de março de 2001, da Petrobras, em cumprimento à Portaria ANP número 14, artigo 30, de 01 de fevereiro de 2000. O derramamento causado pela plataforma foi combatido através de recolhimento de parte do óleo e dispersão química e mecânica da parte do petróleo bruto. O desastre ecológico não se tornou maior porque o fluxo dos poços ligados à plataforma foi interrompido logo após as explosões.

O próximo segmento deste artigo é destinado ao estudo das principais contribuições do acidente com a plataforma P-36 para as melhorias na área de segurança, treinamento dos operadores, no projeto, tentando assim minimizar os acidentes e incidentes nas plataformas de petróleo e gás.

\section{MELHORIAS A PARTIR DO ACIDENTE}

Inúmeros fatores podem coexistir para que ocorra uma explosão em uma plataforma de petróleo e gás. Esses fatores podem estar principalmente relacionados com a manutenção inadequada, falta de treinamento dos funcionários, erros de projetos e operação.

Tendo em vista as causas apresentadas do acidente, para que evite desastres como esse, a Comissão de Investigação ANP/DPC recomenda que sejam adotadas as seguintes medidas: Aprimoramento do sistema de gestão operacional: Revisão e aplicação do sistema de gestão assegurando a exatidão de procedimentos regulamentares, exemplificado pela definição das responsabilidades relativas à manutenção, operação e segurança; Revisão de critérios de projeto: Efetuar a revisão de regras e procedimentos de forma a assegurar proteção de sistemas e componentes críticos de unidades marítimas; Classificação de áreas de risco: Estabelecer critérios para aplicação de normas relativas à classificação de Zonas de Risco; Ações simultâneas de comissionamento, manutenção e operação: Estabelecer critérios que limitam as atividades de comissionamento de forma simultânea com a operação e manutenção de unidades marítimas; Dimensionamento e capacitação de pessoal: Reavaliar o dimensionamento e a qualificação das equipes de operação e manutenção de unidades marítimas, principalmente daquelas responsáveis pela resposta a emergências de grande risco; Gerenciamento de projetos de conversão de unidades: Por em prática regras e procedimentos para tornar compatíveis os sistemas originais e as alterações de projeto de modo a garantir a segurança operacional e a proteção ambiental; Código Internacional de Gerenciamento de Segurança: Avaliar a antecipação da adoção do Código Internacional de Gerenciamento de Segurança, aprovado pela Resolução A 741(18) da Organização Marítima Internacional (IMO), para unidades marítimas; Resposta a emergências de grande risco: Elaboração de plano de emergência e implementação de esquema de resposta a 
situações que envolvam grande risco à garantia de vidas humanas, segurança da navegação, proteção ambiental e propriedade.

A Petrobrás, um ano depois do acidente da P-36, anunciou a instalação de uma caixa-preta em cada plataforma de produção de petróleo em atividade no país. A instalação dessa caixa evitará a perda de informações em caso de afundamento da plataforma, armazenando dados sobre temperatura, pressão, corrosão de tubos, compressão de gás, entre outros. Além disso, declarou que não usará mais bombas com múltiplas funções, pois no acidente da P-36.

\section{CONCLUSÃO}

Neste artigo foi realizado um estudo sobre o acidente na plataforma P-36 da Petrobras, onde foi um grande marco na história do país não só pela poluição marítima, que gerou danos para natureza, mas também pelas mortes que o acidente acarretou o afundamento completo da P-36. Sendo assim esse trabalho teve a finalidade de apresentar as principais causas do acidente, os impactos ambientais e as melhorias que podem ser implantadas para minimizar a possibilidade de novos incidentes.

A relevância do estudo e compreensão das causas e consequências dos acidentes é significativa para os profissionais que atuam na indústria de petróleo no Brasil, pois, mesmo com normas, marcos regulatórios e controles mais rígidos, a exploração do petróleo traz novos desafios tecnológicos. Sendo assim, um aprendizado pautado em estudo de caso, diminui a possibilidade de repetição das mesmas causas responsáveis pelo acidente, evitando expressivos impactos socioeconômicos e ambientais e perdas de vida.

\section{REFERÊNCIAS}

ANP/DPC. Análise do acidente com a plataforma P-36. Relatório da Comissão de Investigação ANP/DPC, 2001.

BOOTH, M. e BUTLER, J. A new approach to permit to work systems offshore. Safety Science, 15:309320, 1992.

SOUZA, A. Planos Nacionais de Contingência para atendimento derramamento de óleo: análise de países representativos das Américas para implantação no caso do Brasil. Trabalho de Mestrado (Mestre em Ciências em Planejamento Ambiental) - Universidade Federal do Rio de Janeiro, UFRJ, Rio de Janeiro, 2006. 